\title{
STUDY AND DEVELOPMENT OF NEW TECHNOLOGIES FOR INTERNAL LIGHTING COMPONENTS
}

\author{
Isabella Luisa Vieira Aquino Cassimiro (CASSIMIRO, I. L.) \\ Fiat Chrysler Automobiles \\ isabella.aquino@external.fcagroup.com
}

\begin{abstract}
This paper intends to study the behavioral patterns of electronic and optical components such as electroluminescence. The proposal consists in to study applications for components in vehicle interior lighting and that they achieve the technical and aesthetic specified by the standards.

\section{INTRODUCTION}

Faced with the industry's challenge to develop new technologies, there is a growing demand for the development of electronic products that emit light as electroluminescence.

The space optimization scenario, energy efficiency, low weight and high durability, made possible the study to apply these components for internal lighting of vehicles.

\section{ARGUMENTS}

The challenge of the research was to understand the parameters involved in electronic technology that allowed the emission of light. With the first step to deepen the knowledge of the proposed technology.

The electroluminescence is an optical and electrical phenomenon. This material emits light in response to an electric current running through it. In terms of the practical field, which means capacitor dielectric material containing particles, in the presence of alternating electric fields can promote electronic transitions triggering emission of photons of a particular wavelength (Kalili, 2013 [1]).

The manufacture of these components constitutes electroluminescent material deposition on a substrate base and subsequent compression of substances. (Turatti, 2003 [2]).

At the end of the process, one can find a nearby a tape format as shown in figure 1.
\end{abstract}

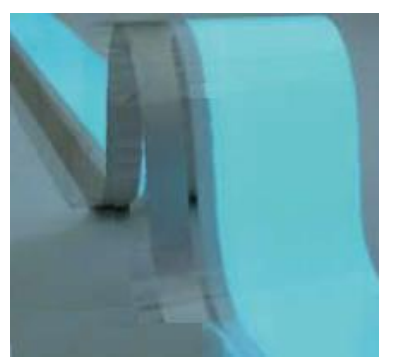

Figure 1. Blue Tape electroluminescence.

As can be seen in Figure 1 the component dimensional appearance can be compared to a tape thickness close to 0.7 millimeters. 
To understand the chemical composition of the studied part, a micro graphic section is required, Figure 2 illustrates a micrograph of the cross section.

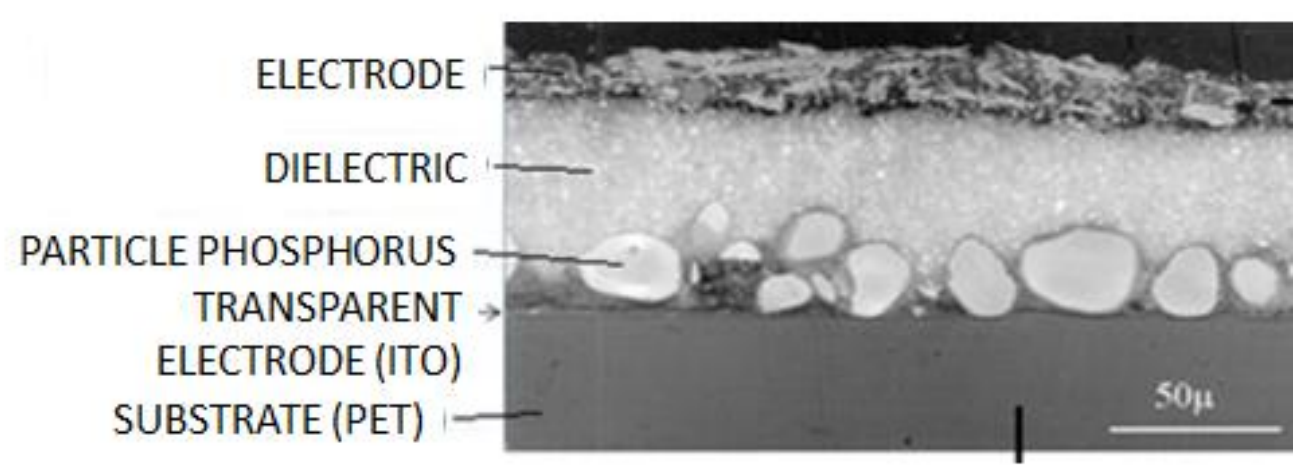

Figure 2. micrograph of the cross section of the studied prototype.

In this study prototype, one should take into account the substrate preparation for the deposition of other materials. The material used for manufacturing the said substrate and PET (polyethylene terephthalate).

PET is a thermoplastic polymer formed by reaction between terephthalic acid and ethylene glycol. Its mechanical and thermal properties allow you to build flexible and resistant components (MANO, 1999 [3]).

Above the PET is the transparent electrode, ITO (Indium Tin Oxide), that is, indium oxide doped with tin. This material is a semiconductor of high transparency in the visible spectrum, in addition to its high electrical conductance, occurring him to the passage of electric current.

Another property of ITO is their shape memory, which enable the manufacture of this electronic device because, when deformed do not lose functionality (Heavens, 1991 [3]).

The electric field formed by the electrode excites the phosphor electrons are deposited on top of it. Moreover, it is due to the passage of electric current in the phosphor which is all the light emission phenomenon (Burini, 2014 [5]). Figure 3 summarizes the configuration of the section shown above.

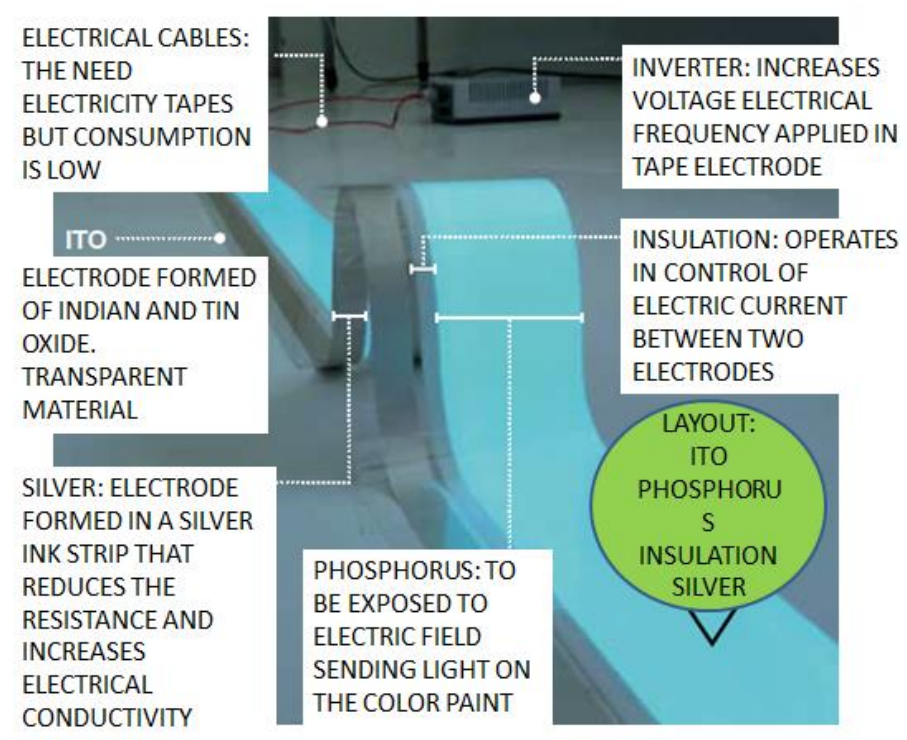

Figure 3. Summary of the materials that make up the flexible tape. 
The component of the operating principle consists of applying a variable electric field formed by the silver electrodes and ITO that excite the phosphor's electrons. When the phosphor electrons return to the original state, emit red light, white, blue, or green, this phenomenon depends on the color type of the ink used with the silver.

The colors available today are red, white, blue and green, and matching analysis with the car's interior is based on the following chromaticity coordinates of Table 4, provided by the component supplier.

Table 4. Coordinates of colors available for this application.

\begin{tabular}{|c|r|}
\hline COLOR & COORDINATED BY NORM CIE1931 \\
\hline BLUE & $x=0,13 ; \quad y=0,05$ \\
\hline GREEN & $x=0,18 ; \quad y=0,71$ \\
\hline RED & $x=0,71 ; \quad y=0,29$ \\
\hline WHITE & $x=0,30 ; \quad y=0,31$ \\
\hline YELLOW & $x=0,57 ; \quad y=0,42$ \\
\hline
\end{tabular}

The studied ribbon manufacturing process is based on the printed electronics technology, rollers are used in the manufacture of organic semiconductors.

The tapes are manufactured in a so-called roller printing press roller which functions similar to a newspaper rotary manner.

Figure 5 is one of the machines used today for printing of electroluminescence studied.

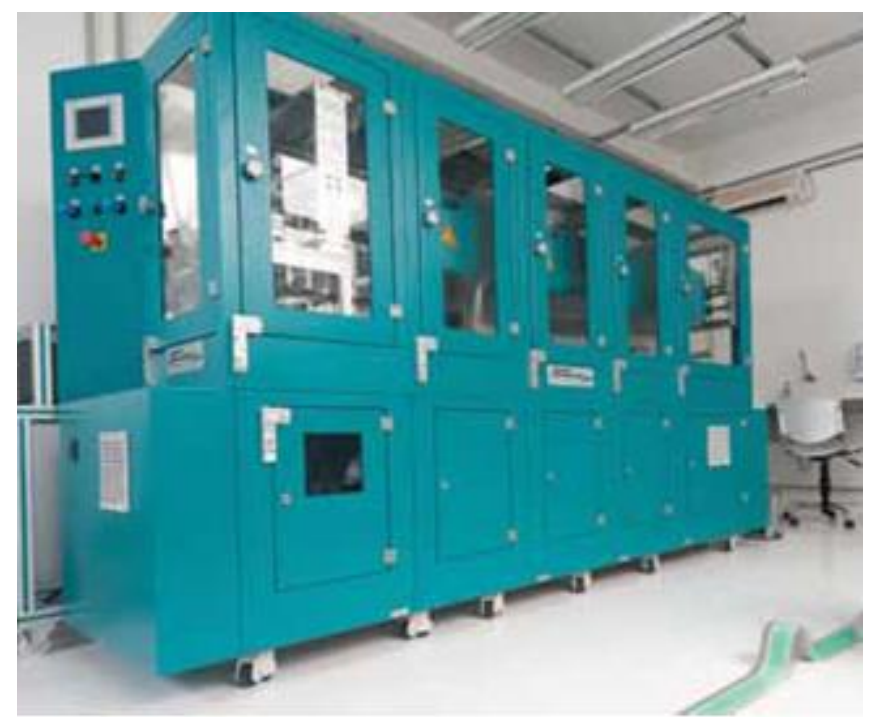

Figure 5. Machine used for manufacturing the tapes.

After the study of the technology that has been proposed, the next step is to develop a preliminary concept of application. Therefore, we proposed some regions and functions which would be feasible to develop these components.

The areas explored were:

1. Brand model

2. instrument panel Screen printing

3. "Designs" in specific fabrics and carpets 
They were traced some methods for making prototypes and tests to validate parts, namely:

I. Set the viewing angle necessary

II. Set dimensions

III. Set thickness

IV. Need or light reflection restrictions

V. Needed Power Consumption

VI. Life component

VII. Generated heat quantity

VIII. Check the sense of comfort for the client

IX. Water resistance and heat

$X$. Homogeneity of the light

XI. Component Weight Resistance mechanical

Based on the concepts mentioned above were made prototype in conjunction with the supplier to be validated.

Figures 6, 7.8 and 9 demonstrate each application and compares it to the current solution of production when applicable.

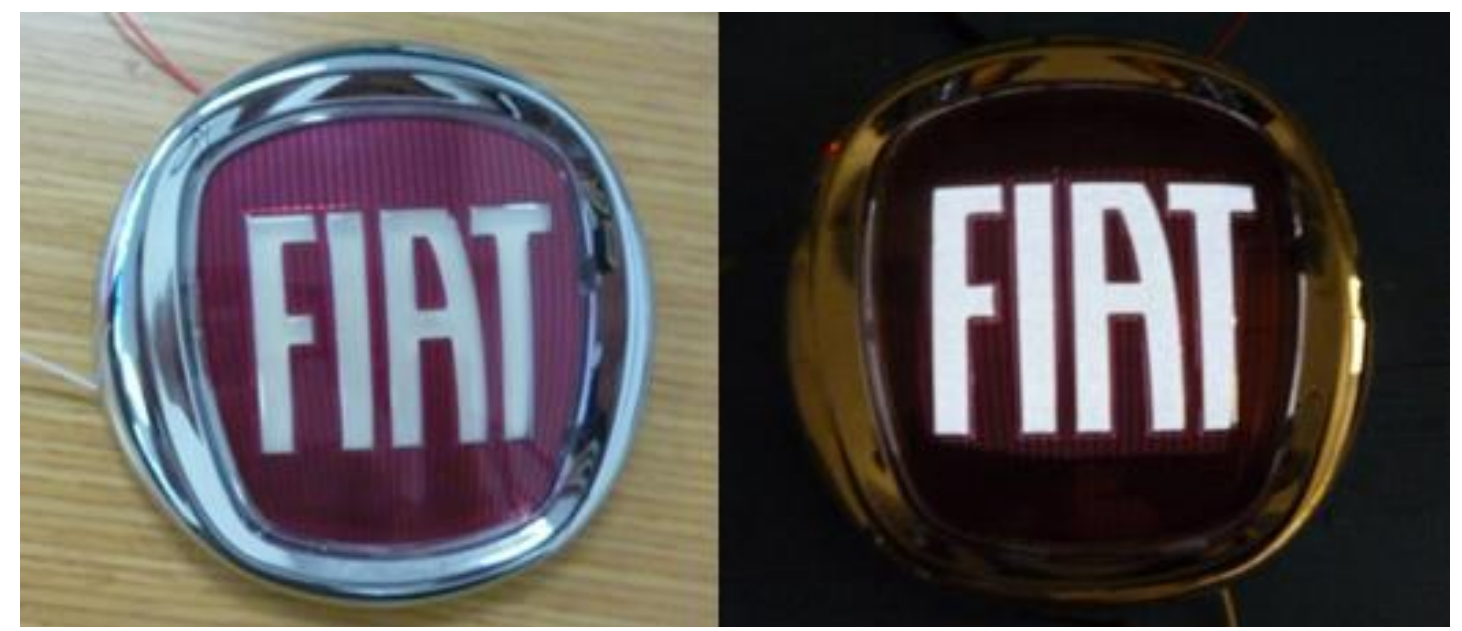

Figure 6. Fiat brand fixed on the steering wheel, the right image is the current production and the left region of the letters are illuminated by the electroluminescent strips.
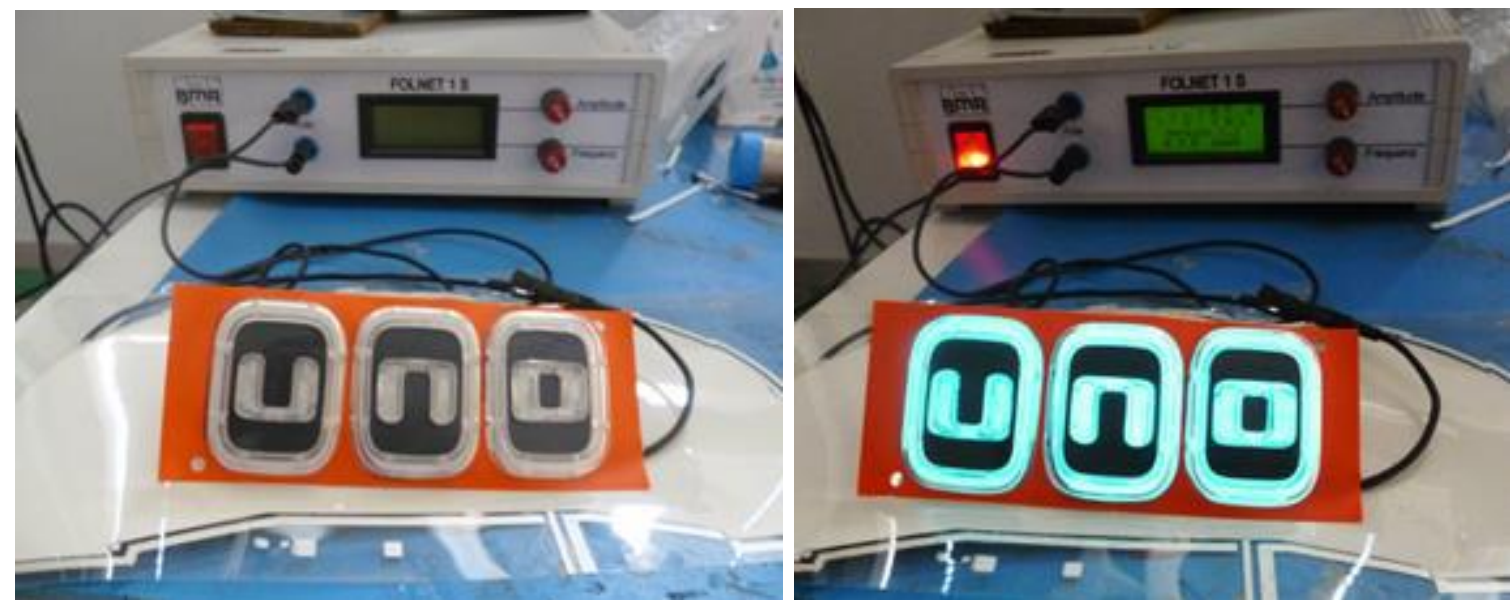
Figure 7. When the name of the model laid down in the door panel, right image is a proposed name unlighted model and left a proposal of the letters and edges illuminated by the electroluminescent tape.
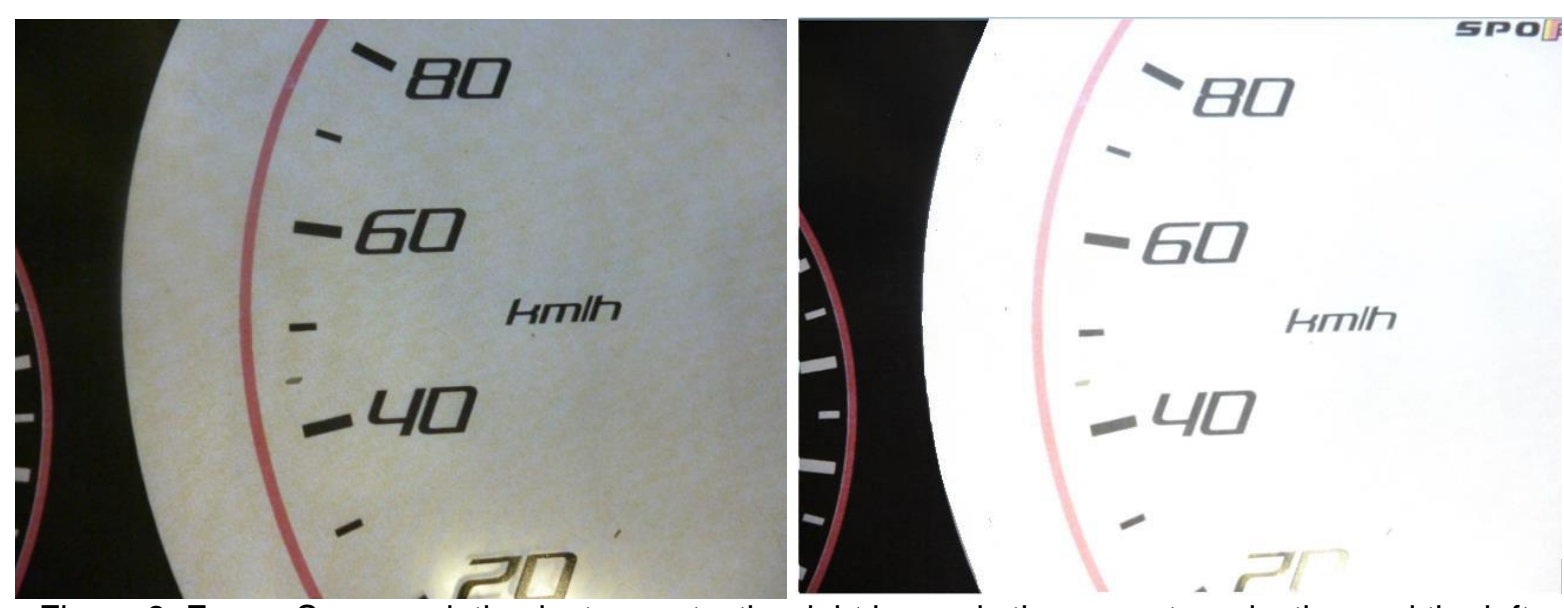

Figure 8. Frame Screen printing instruments, the right image is the current production and the left with the electroluminescent strips.
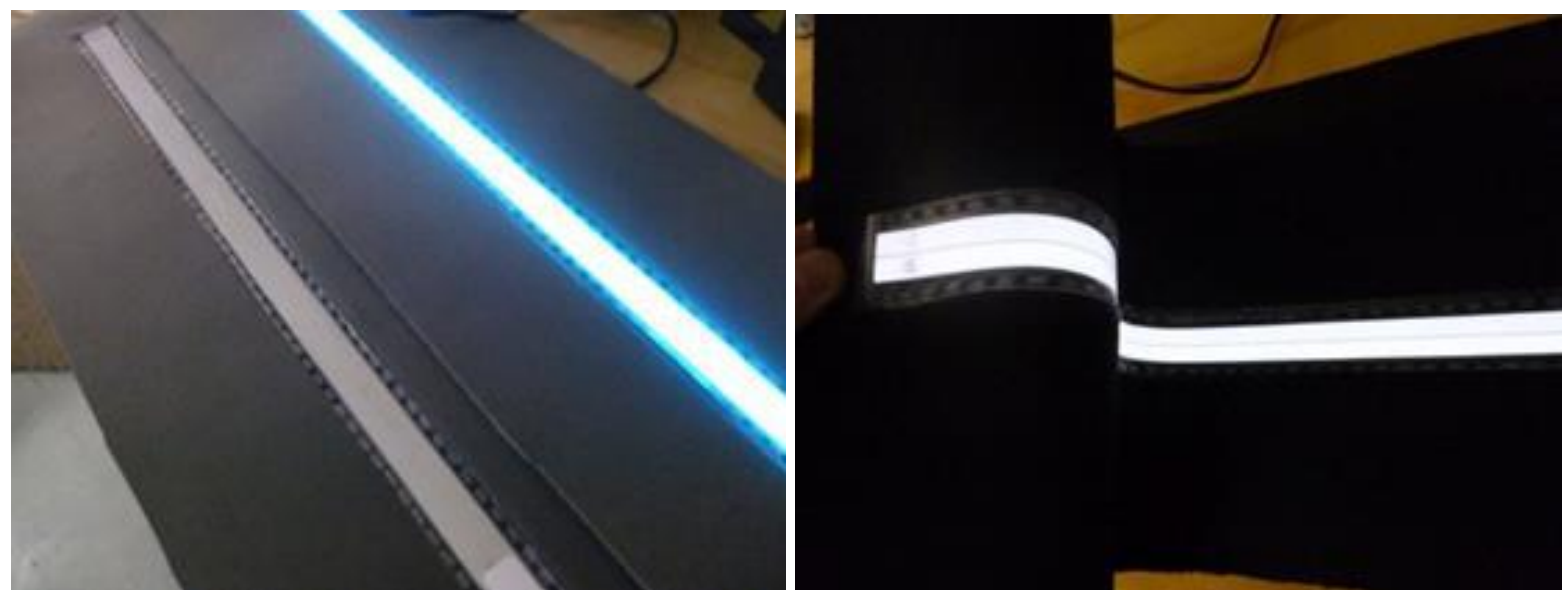

Figure 9. Integration with fabrics and carpets, right image compares the lit and unlit ribbon panels of fabric and left the tapes were applied to carpets.

For validation of prototypes, internal rules Fiat and empirical methods due to the complexity of the technology in some unforeseen internal rules cases were used. The following methodology and test sequence based on local rules:

1. 9.93348 (regulates components features for interior lighting)

2. $55210 / 01$ (thermoplastic regulates)

3. 9.90111 (electromagnetic compatibility)

The following topics in evaluated prototypes:

1. visual aspects;

2. dimensional;

3. photometry;

4. electrical Characteristics;

5. electromagnetic characteristics; 
6. resistance to thermal cycling;

7. resistance to corrosion and water;

8. resistance to chemical agents;

9. vibration resistance;

10. resistance to fatigue;

During the tests it was found that for each proposed application component showed a behavior in relation to this aspect.

The most critical case checked refers to the EMC standard (electromagnetic compatibility).

EMC tests have shown the influence of the dimensional characteristics, for electromagnetic compatibility is the ability of two devices (electronic or electrical) to operate in a given environment, generating electromagnetic disturbances differently, it is necessary to remain within acceptable standards operation (MOLOGNI, 2010 [6])

However, each variation in the dimensional application proposal needs to be reevaluated and validated in this test. Another factor found of great influence on the behavior of the material, was installed zone because in places where the tightness is not guaranteed may occur to the water supply, it is not feasible to application of technology.

Corrosion tests showed stains and defects such as Figure 10 may illustrate.

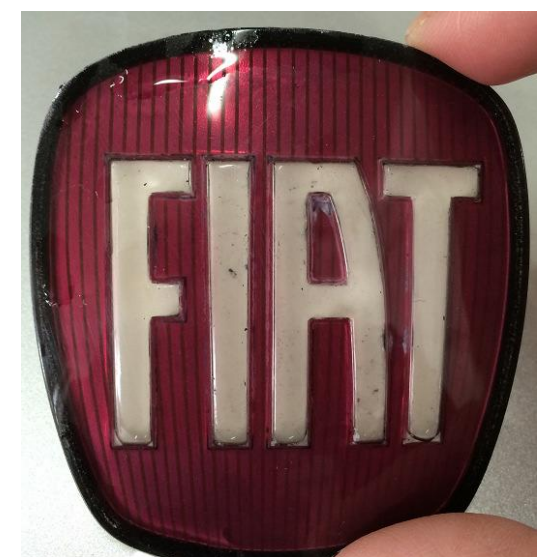

Figure 10. Stained Visual appearance after corrosion resistance tests and water.

As shown in the image above for each proposed application, it must ensure component tightness in order to provide the service life of the component.

Among the observed characteristics, the temperature was one of which most influenced the life of the material.

The graph 11 illustrates the shelf life of the material reduction with the rise in temperature in a specified time.

This chart has been provided by the manufacturer that demonstrated the expected component lifetime taking into account the temperature increase. 


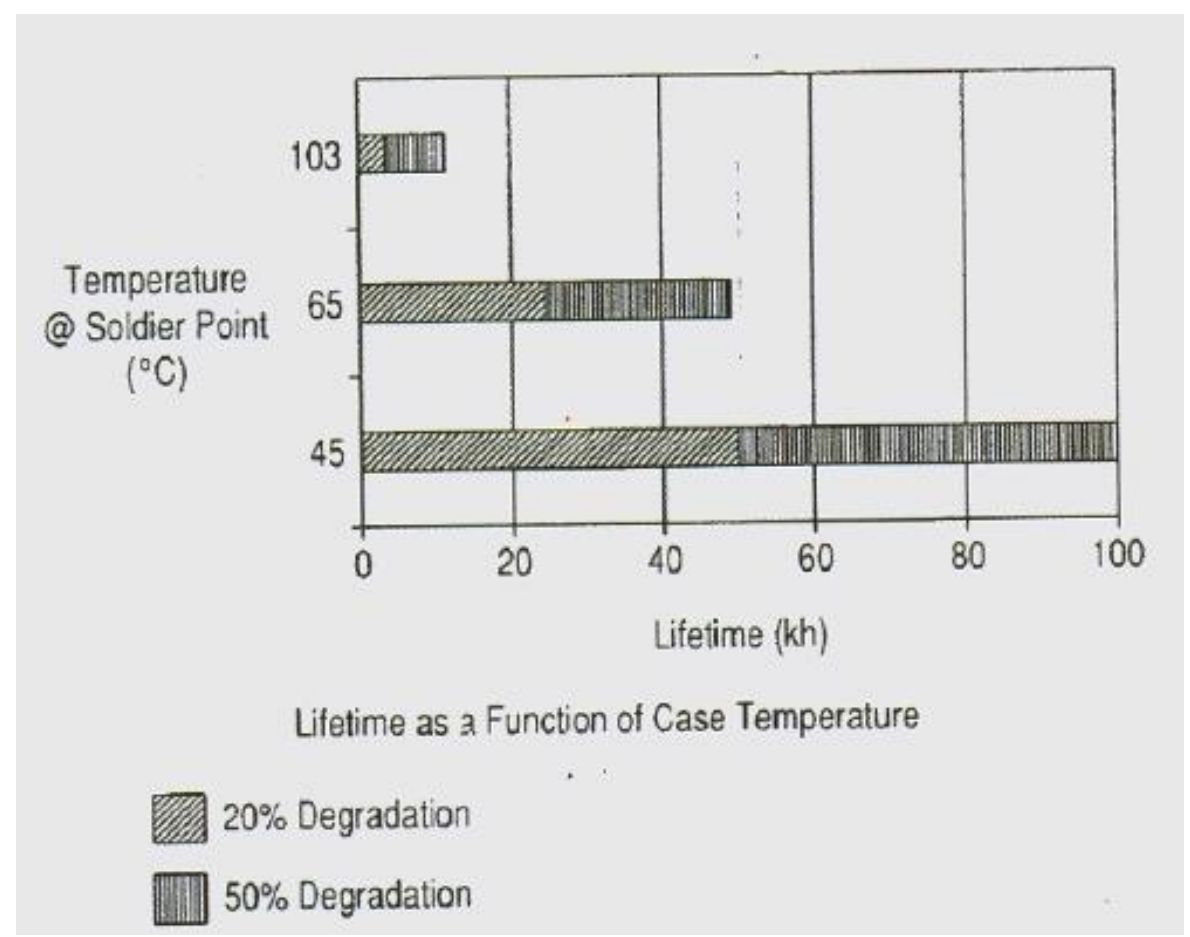

Figure 11. Reduced useful life of the material with the temperature rise in time.

On the data and information collected during development, it appears that the influence of the installed area, the dimensions of the piece and temperature, should define the best application for electroluminescence in the car.

\section{CONCLUSION}

It has been demonstrated many cases of application of electroluminescence in vehicle parts. This will enable the FIAT, the creation of new functional concepts for lighting the interior of the automobile.

The manufactured prototype components generated a high visual impact that shows a potential application of the studied technology.

Several knowledge was acquired during the development of the application such as: mechanical, optical, thermal, electrical and electronic materials, this study allowed us to understand the main points to be able to define strategies to validate and qualify the possible applications of electroluminescence.

Created a development methodology of electronic components light emitters for indoor lighting vehicles. This may support the development of work instructions that standardize the installation of new lighting. 


\section{REFERENCES}

[1] kalili, Sérgio. Iluminação flexível. search fapesp, Belo horizonte, Pag 11, 2013.

[2] Turatti, L. G. WTPrrocess: Uma ferramenta para ensino de micro fabricação. Dissertaçaõ (Mestrado), Unicamp, Campinas, 2003.

[3] MANO, Eloisa Biasotto. Introduction a Polymer. $2^{\mathrm{a}}$ ediction. São Paulo: publishing company Blücher, 1999.

[4] Heavens, O. S. Optical Properties of Thin Solid Films. Courier Dover. Publications, pag 17, 1991.

[5] Burini, Elvo; Calixto, Emerson Roberto Santos. Nanoeletrônica: Dispositivos eletroluminsecentes para iluminação artificial. Available in http://www.iee.usp.br/biblioteca/producao/2013/Artigos\%20de\%20Periodicos/burinin anoeletronica1.pdf : 03/02/2014.

[6] MOLOGNI, J., ET AL. Accelerating the Vehicle Development Process by Employing EMI and EMC Numerical Analysis Assisted by High Performance Computing. SAE Technical Paper 2010-36-0037, 2010. 